\title{
TAMANHO E ESTRUTURA FAMILIAR DE IDOSOS RESIDENTES EM ÁREAS PERIFÉRICAS DE UMA METRÓPOLE*
}

\author{
FAM ILIAR STRUCTURE AND SIZE OF SENIOR LIVING \\ IN PERIPHERIC AREASIN A METROPOLIS
}

\author{
TAM AÑ O Y ESTRUCTURA FAM ILIAR DE ANCIANOS RESIDENTES \\ EN ÁREAS PERIFÉRICASDE UNA METRÓPOLIS
}

\author{
MARIA JOSEFINA DA SILVA**, MARIA ELIANE PEIXOTO BESSA*** \\ EADRIANA MARIA CARDOSO DE OLIVEIRA****
}

\begin{abstract}
RESUMO
A família éo esteio do idoso, seja afetivo, como suporte para o cuidado, e financeiro, quando sua renda éinsuficiente para seu auto-sustento. M as a família está reduzida em seu tamanho e seus valores sofrem fortes transformações. 0 estudo objetivou conhecer tamanho e estruturas familiares de idosos residentes em áreas de baixa renda. Trata-se de um estudo descritivo, cujos sujeitos foram selecionados a partir do cadastramento dos agentes de saúde. A sel eção da amostra foi estratificada, aproximando-se do perfil da população da área nas variáveis sexo e faixa etária, totalizando 100 idosos. A coleta de dados se deu no período de dezembro de 2002 a abril de 2003, em visitas domiciliárias realizadas por estudantes de iniciação científica treinadas. Concluímos que a família com idoso está reduzida de tamanho quando este mais precisa dela, isto é, em idade avançada. Os homens conseguem manter uma estrutura familiar por mais tempo; a renda familiar é baixa; o número de membros desempregados é alto, e a idade dos que residem com 0 idoso também é el evada donde se conclui que a realidade estudada não é favorável ao idoso.
\end{abstract}

Palavras-chaves: M embros da família, tamanho da família, idoso, núcleo familiar.

\section{RESUMEN}

La familia es el apoyo del anciano, sea afectivo, como soporte para el cuidado, y financiero, cuando su renta es insuficiente para su autosustento. Pero la familia se ve reducida de tamaño y sus valores sufren fuertes transformaciones. El estudio tuvo el objetivo de conocer tamaño y estructuras familiares de ancianos residentes en áreas de baja renta. Se trata de un estudio descriptivo, cuyos sujetos fueron seleccionados a partir de la afiliación de los agentes de salud. La selección de la muestra fue estratificada, aproximándose al perfil de la población del área en las variables sexo y edad, totalizando 100 ancianos. La colecta de los datos se efectuó en el período de diciembre a abril del 2003, en visitas domiciliarias real izadas por estudiantes de iniciación científica entrenadas. Llegamos a la conclusión de quela familia con anciano se ve reducida de tamaño cuando éste más precisa de ella, esto es, con edad avanzada. Los hombres consiguen mantener una estructurada familiar por más tiempo; la renta familiar es baja; el número de miembros desempleados es alto, y la edad de los que residen con el anciano también es el evada con lo que se llega a la conclusión de que la realidad estudiada no es favorable al anciano.

Palabras claves: M iembro de la familia, tamaño de la familia, anciano, núcleo familiar.

\footnotetext{
*Este artigo é parte integrante da Pesquisa "O idoso dependente e o universo do cuidado domiciliar", financiada pela FUNCAP - Fundação Cearense de Apoio ao Desenvolvimento Científico e Tecnológico e Ministério da Saúde do Brasil, ainda em desenvolvimento.

**Enfermeira, professora Departamento de Enfermagem da Universidade Federal do Ceará-Brasil. E-mail: mjosefina@terra.com.br

***Aluna de graduação do Curso de enfermagem da U FC. Bolsista de Iniciação à Pesquisa/PIBIC/CN Pq.

****Aluna de graduação do Curso de enfermagem da UFC. Voluntária do Projeto de pesquisa 0 Idoso Dependente e 0 universo do cuidado domiciliar do qual esta investigação é parte integrante.
} 


\section{SUMMARY}

The family is the home to the senior, being affective, as support to the care, and finances, when his income is not enough to his self-living. But the family is reduced in its size and its values suffer strong transformations. The aim of this study was to know familiar structures an size of seniors living in areas of low income. This is a descriptive study, whose subjects were selected from the subscription of health agents. The sample's selection was stratified, nearing from the profile of the population of area in the variables gender and age, totalizing 100 seniors. Data collection took place during the period of december/2002 to april/2003, in home visit done by trained scientific initiation students. We concluded that the family with the senior is size reduced when this one, needs it, the most, or better, in advanced age. The men get to keep a familiar structure for a longer time; the familiar incomeislow; the number of unemployed members is high, and the age of the ones that live with the senior is elevated al so where we conclude that the reality studied is not favorable to the senior.

Keywords: Family's members; family's size; senior; familiar core.

Recepcionado: 12.11.2003. Aceptado: 21.04.2004

\section{INTRODUÇÃO}

Mais do que em qualquer outro período ao longo do curso devida, o idoso precisa deuma relação direta, estreita e duradoura com a família. Esta é o eixo de significância para seu cotidiano. É nela que o idoso realiza suas relações afetivas e significantes; espera a segurança e o apoio necessário para que continue vivendo sua velhice autonomamente, de modo que seja bem sucedida (N éri, 1999). Desta forma ele espera manter os espaços vitais que lhe permitam privacidade, aconchego e preservação da sua história.

No Brasil, a lei $n=8.842 / 94$ que instituiu a Política Nacional do Idoso - PNI, em seu artigo 10 destaca a necessidade de assegurar os direitos sociais do idoso e, em seu artigo 3ㅇ, apresenta seus princípios: “I- a família, a sociedade, 0 estado têm o dever de assegurar ao idoso todos os direitos de cidadania, garantindo sua participação na comunidade, defendendo sua dignidade, bem estar e direito 'a vida (...)" (Brasil, 1994). O Estatuto do Idoso, lei $\mathrm{n}$ - 10.741 de 1 de outubro de 2003, 0 ampara nos mais diferentes aspectos da vida cotidiana, mas destaca o papel da família em todos eles. No art 30 reforça a lei 8.842 quando enfatiza obrigação da família, da sociedade e do poder público assegurarem o direito à saúde, alimentação, cultura, esporte, lazer, trabal ho, cidadania, liberdade, dignidade, respeito e convivência familiar (Brasil, 2003).
A Organização das Nações Unidas (ONU) adotou os princípios em favor das pessoas de idade, Resolução 46/91 de 16/12/1991, exortando os governos a incorporarem estes princípios na medida do possível. São destacados os seguintes aspectos: independência, participação, cuidados, autorealização, dignidade. No aspecto: cuidados, está posto que as pessoas idosas devem desfrutar dos cuidados e da proteção da família e da comunidade, de conformidade com os val ores culturais ecada sociedade (ONU, 2000).

Mas que família é essa? De um modo geral, estudos relacionados à família nos aspectos culturais, de arranjos familiares, de estrutura, de espaço emuitos outros, ainda queem número reduzido no país, concordam quesão cada vez mais inadequadas à permanência do idoso em seu seio. A evidência empírica da importância da família para o idoso surge, para as pesquisadoras, do contato permanente com idosos, seja durante a consulta de enfermagem em unidades de saúde onde se realizam as atividades de prática disciplinares, nas reuniões do grupo de convivência deidosose na visita domiciliária a estegrupo. As queixas mais freqüentes nestes contatos e confirmadas por pesquisa empírica (Silva, 2001; Araújo, 2003) são: 0 descuido do familiar para com o idoso; a inadequação de moradia; a falta de pessoas para ajudar no cuidado; escassos recursos financeiros; inacessibilidade aos recursos comunitários, incluindo os de saúde e o 
padrão de relacionamento entre os membros da família, na maioria das vezes excluindo o idoso do convívio familiar.

A família contemporânea, cujo modelo hegemônico é o nuclear, tem como características a mobilidade, o tamanho reduzido, a fragilidade dos laços matrimoniais; a saída da mulher para o trabalho extradomiciliar, 0 distanciamento dos parentes, a perda do sentido de responsabilidadecom as gerações mais velhas (FGV, 1986, p. 457-8). Neste cenário, quefaz partedo cotidiano da enfermagem que trabal ha na saúde coletiva, o idoso perde espaço, papel efunção social.

Para o presente estudo, adotamos o conceito de família expresso na Constituição Federal do Brasil, segundo a qual a família "é a base da sociedade, tem especial proteção do estado. (... ) Para efeito de proteção do Estado, é reconhecida a união estável entre o homem e a mulher como entidade familiar, devendo a lei facilitar sua conversão em casamento. Entende-se também como entidade familiar a comunidade formada por qualquer um dos pais e seus descendentes" (art. 226 , parágrafo 2o e 3‥ Brasil, 2003, p. 132).

Foram estas evidênciasteóricas eempíricas que nos levaram a decidir estudar as estruturas familiares dos idosos residentes em áreas de baixa renda. Nosso objetivo foi conhecer como as famílias com idoso se estruturam e qual o seu tamanho. Acreditamos que este conhecimento propiciará atuação dos profissionais de saúdee, em especial, a enfermeira, por trabalhar mais diretamente com famílias, demodo a direcionar asintervenções mais próximas à realidade do idoso. Acreditamos também poder construir coletivamenteestratégias que viabilizem uma melhor adequação do idoso aos modelos familiares e vice-versa, de modo a proporcionar maior autonomia para nosso cliente idoso.

A relevância deste estudo para a enfermagem se evidencia quando a PNI enfatiza a permanência do idoso na família, implicando que esta tenha condições para preservar a qualidade de vida do seu ente idoso, muitos deles com dependência para as atividades de vida diária em função de doenças crônicodegenerativas, situação em que a família e a enfermagem assumem papéis de colaboração e complementadade (Turini et al., 2002).

No Brasil, o Programa de Saúde da Família coloca como foco de sua prática a abordagem familiar, impondo a necessidade de se debruçar teoricamente sobre o tema para dar conta da complexidadeestrutural econceitual de problemas até então invisíveis à prática da enfermagem.

O trabal ho com família, embora seja uma prática tradicional na enfermagem, só foi alvo deteorização há bem pouco tempo. Whighte Leahey (2002), em seu livro Enfermeiras efamília, evidenciam esta lacuna elembram que - M odelo Galgary de avaliação da família éo único modelo para enfermeiras e de autoria de enfermeira.

\section{MATERIAL E MÉTODOS}

Trata-se de um estudo descritivo, com dados numéricos, cujos sujeitosforam selecionados a partir do cadastramento dos agentes comunitários de saúde pertencentes a SER III ${ }^{1}$ nos bairros Pici eDom Lustosa, cuja população é, predominantemente, de baixa renda. A seleção da amostra foi estratificada, aproximando-se do perfil da população da área nas variáveis sexo e faixa etária, em um total de 100 idosos, representando 3,6\% da população total da área. Os residentes na área do estudo partilham de condição social, econômica, educacional semel hantes, além do quea maioria tem um mesmo padrão de cultura familiar, o que possibilita inferência para um grupo semelhantedeidosos. 0 instrumento para

${ }^{1}$ Secretaria Executiva Regional III. A cidade deFortaleza (Ceará-Brasil) foi dividida em 6 áreas, cada uma com uma secretaria responsável pela administração da sub-área nos setores que estão diretamente ligados às questões de saúde segundo o paradigma adotado. São elas: educação, saúde, desenvolvimento social, geração de emprego erenda, limpeza pública. 
coleta de dados foi um formulário contendo dados sobre membros da família do idoso: relação de parentesco; idade, ocupação, escolaridade, sexo, renda pessoal ereligião. As entrevistas foram realizadas na residência do idoso e as informações foram prestadas pelo próprio idoso e/ou familiar quando o primeiro não detinha o conhecimento das informações necessárias, sempre com a presença dos agentes comunitários de saúde da área. A coleta de dados se deu no período de dezembro de 2002 a abril de 2003 por 1 acadêmica de enfermagem e 1 bolsista de iniciação científica treinadas. 0 formulário foi previamente testado e reajustado de modo a atender ao objetivo. 0 longo prazo de coleta deveu-se a dificuldades deacesso aosidosos, a dificuldade de compatibilizar horários por parte dos pesquisadores e agentes comunitários dede saúde que acompanharam as visitas; as características da área de estudo ${ }^{2}$ e a chuvas, intensas no início de janeiro até o término da coleta de dados. Esta pesquisa foi aprovada pelo Comitê de Ética em Pesquisa com seres humanos da Universidade Federal do Ceará segundo a Resolução 196/96 do M inistério da SaúdeM EC, 2004), fazendo parte deum projeto de pesquisa que estuda o cuidado domiciliar do idoso e seu cuidador, ainda em andamento. Cada participante foi informado antecipadamentedo objetivo, da metodologia equal a finalidade da mesma, enfatizando sua participação voluntária. Não houve recusa, acreditamos por termos a colaboração dos agentes de saúde as áreas que mantêm com a população uma relação fortedeconfiança. Ao término do projeto, os resultados serão apresentados na UBSF cuja área foi realizado o estudo, uma vez que outros aspectos abordados na pesquisa ainda estão em fase de análise.

²Por ser uma área considerada de alto risco, pela violência e marginalidade decorrente pelo al to consumo de drogas entre os adolescentes residentes na área. Na ocasião houve demissão de quase to dos os agentes de saúde o que noslevou a não dar continuidade a coleta de dados devido ao alto risco das bolsistas irem às residência dos idosos sozinhas.

\section{RESULTADOS}

\subsection{Características dos entrevistados}

Foram entrevistados 30 (30\%) do sexo masculino e 70 (70\%) do sexo feminino.. A faixa etária predominante foi de 60- 65 anos, com $22(31,4 \%)$ mulheres e a de $75-80$ com 11 $(36,6 \%)$ dehomens. Embora não retratecom fidedignidade a distribuição da população segundo sexo, tivemos dificuldades para entrevistar os homens, pouco afeitos a participarem da pesquisa.

Segundo a terminologia adotada por $\mathrm{Me}$ deiros e Osório (2002) quanto aos núcleos familiares: composto (o casal) esimples (apenas um membro e predominantemente a mulher), obtivemos o seguinte resultado: 27 (90\%) dos entrevistados do sexo masculino residem em famílias cujo núcleo familiar é composto. Quanto às mulheres, apenas 22 $(31,4 \%)$ se encontram em famílias com estas características. Das idosas, cujo núcleo familiar ésimples (68,5\%), as que estão nas faixas etárias de 60 a 42 anos (13) eacima de 80 anos (13) representam, cada uma 27,0\%.

Em relação a idade entre os cônjuges, as idosas da faixa etária mais jovem (60-64 anos), tinham, num percentual de $66,4 \%$, maridos/ companheiros mais velhos. Na faixa etária de 65-70 anos, 83,3\% estavam nesta condição; de 71-74 anos este percentual éde $100,0 \%$, semeIhante à faixa etária de maiores de 80 anos.

No caso dos idosos entrevistados, suas esposas/companheiras, eram mais jovens, majoritariamente, em todas as faixas de idade, a saber: $60-65$ an os; $85,7 \%$; $65-70$ anos; $100,0 \%$; 71-74 anos: $71,4 \%$; $75-80$ anos: $85,7 \%$ e na população acima de 80 anos este percentual foi de $100,0 \%$.

\subsection{Estrutura familiar}

Quanto à caracterização da estrutura familiar dos idosos, foram consideradas as seguintes variáveis: tipo de família; renda familiar; 
idade, sexo, escolaridade, profissão, estado civil, religião dos membros da família. Categorizamos os tipos de família em: nuclear: quando écomposta pel o casal efilhos podendo incluir netos; extensa: quando além do grupo nuclear, incluem-se outros parentes; incompleta: quando apenas um dos cônjuges compõeo núcleo (simples) seja por viuvez ou separação; morando só ecom parentes: quando as pessoas com as quais o idoso convive são irmãos, primos ou outros parentes mais distantes.

Deacordo com esta forma de organização dos dados, pudemos observar os seguintes arranjosfamiliares: a família nuclear foi o tipo predominante $(42,0 \%)$, seguido da incompleta (32,0\%). Ao compararmos os arranjos em relação ao sexo do entrevistado, observamos que apenas $28,6 \%$ das idosas residem em famílias nucleares, em oposição aos homens, os quais $73,3 \%$ estão nesta situação. As mulheres têm famílias incompletas em $42,8 \%$ dos casos analisados e os homens $6,6 \%$. Um número considerável deidosas residem com parentes $(11,4 \%)$, predominando as de faixa etária entre 60 e 64 anos. Todos os idosos que residem sozinhos (7) são do sexo feminino.

\subsection{Renda familiar dos idosos entrevistados}

Segundo a faixa etária dos entrevistados, a renda familiar se apresentou com as seguintes características: os valores da renda predominantes foram: um salário mínimo ${ }^{3}$, cujo valor é, no momento de $R \$ 240,00$ ou aproximadamenteU $\$ 80,00$, com um percentual de $25 \%$ dos entrevistados e com renda entre 3 e 5 salários mínimos encontramos $25,0 \%$ dos entrevistados, incluindo a aposentadoria do idoso. Cabe destacar que a faixa de renda de

${ }^{3}$ Assegurado pela Lei Orgânica da Assistência Social LOAS (M PAS, 1997, p. 14/5), instituída na Constituição de 1988, na seção IV - Da assistência social, art. 203, item V: “a garantia de um salário mínimo de benefício mensal (...) ao idoso que comprove não possuir meios de prover à própria manutenção ou de têla provida pela família (...)" (Brasil, 2003, p. 124) e referendada na Política Nacional do Idoso. menos de 1 salário mínimo representou $18,0 \%$ das famílias. Aqui também se incluem os que declaram não possuir renda. Assim 0 fizemos, pois pressupomos que não se vive sem nenhum tipo de renda, mesmo que seja advinda de serviços temporários, esporádicos e auxílios de particulares.

Se somarmos os três primeiros níveis de renda (até 2 salários) temos $62,0 \%$ da população estudada.

\subsection{Caracterização dos membros das famílias dos idosos}

Sobre a caracterização das famílias dos idosos entrevistados consideramos os seguintes resultados: residindo com as mulheres idosas temos um total de 254 pessoas, com uma mé dia de 3,6 pessoa/idoso. Os membros maiores de 60 anos constituiu-se a faixa etária predominante, num total de 98 pessoas ( $38,6 \%$ ), seguido do grupo de 20 a 40 anos com 69 residentes $(27,1 \%)$. A população abaixo de 10 anos é de apenas $8,6 \%$ e de adolescentes de $11,8 \%$.

Residindo com os idosos entrevistados encontramos 123 pessoas, com uma média de 4,1 pessoa/idoso. Quarenta e três por cento (53) dos residentes tinham idade acima de 60 anos, segundo da faixa etária de 20-40 anos com um total de 33 pessoas ( $26,8 \%$ ).

Embora possa parecer similar, o tamanho dasfamílias, considerando sexo, merecem ser destacas.

Na medida em que a idade da idosa aumenta, o número de pessoas que convivem na mesma família diminui: as idosas entre 60 e 64 anos têm famílias com, em média, 4 membros. Na faixa etária de 75-80 anos, esta média cai para 2,6 pessoas. Acima de 80 anos a média é semel hante a faixa etária mais jovem: 4 membros.

O mesmo não acontececom asfamílias dos idosos entrevistados que mantêm uma constância no seu número, acima de 4 membros/ família. 
No que diz respeito ao sexo dos residentes com os idosos, não houve diferenciação significativa para os dois segmentos deentrevistados. Nos dois grupos houve mais mulher, $51,2 \%$ dos residentes para os idosos e $59,4 \%$ para as famílias cuja entrevistada foi umaidosa. A exceção ficou por conta das residentes com as idosas acima de 80 anos, quando $75 \%$ dos membros das famílias foram mulheres.

A escolaridade dos membros das famílias das idosas foi mais baixa, com $42,1 \%$ destes analfabetos ou apenas alfabetizados. $\mathrm{Na}$ mesma situação, estão $38,9 \%$ dos que residem com os idosos. 0 destaque está para 12,2\% dos residentes com idosos terem cumprido 0 ensino médio, enquanto apenas $6,6 \%$ estão nesta situação residindo com idosas.

Segundo os dados obtidos, 33,0\% dos residentes com idosas são aposentados, 25,1\% estão desempregados e $22,1 \%$ tem al gum tipo de emprego, formal ou não. No grupo que reside com idosos entrevistados estes percentuais são: $23,5 \%$ são aposentados e o mesmo percentual seencontra desempregado. Osque trabalham representam $36,7 \%$ dos membros das famílias.

A propósito do estado civil, constatamos que $55,1 \%$ dos que residem com as idosas são solteiros, $31,1 \%$ vive com um companheiro, com casamento formal ou não e $13,7 \%$ são viúvos. Com os idosos, $52,3 \%$ dos residentes são solteiros, 43,9\% são casadoseapenas 3,2\% estão na condição de viúvos. Grande parte destes viúvos são as próprias idosas entrevistadas eno caso dosidosos são familiares, uma vez que não houvenenhum idoso entrevistado nesta condição.

A religião católica é hegemônica entre os membros das famílias, com maior ênfase no grupo das entrevistadas (81,5\%) e uma tendênciajámarcantedas religiões evangélicasnas famílias dos homens entrevistados (19,5\%). É interessanteobservar quenuma mesma família encontramos as duas formas de religiosidade coexistindo.

\section{DISCUSSÃO}

\subsection{Características dos entrevistados}

A velhice é feminina. Esta constatação é feita pelos estudiosos do processo do envelhecimento, evidenciando um fenômeno quevendo sendo explorado ainda sem respostas conclusivas. Em Fortaleza-Ceará, a população acima de 60 anos é de 40,2\% de homens e $59,8 \%$ de mulheres, seguindo a tendência nacional. As mulheres têm maior índice de sobrevida do que os homens, quando atingidas pelas principais causas de morte, mas 0 contraponto é que elas são mais afetadas por doenças não fatais. Esta constatação é referida por Hayflick (1997, p, 3) quando afirma que" 0 aumento da longevidadesignifica mais tempo para sofrer destas doenças".

Por ser feminina e pelos valores culturais que limitam a mulher constituir um novo casamento após a viuvez, a velhice trás a muIher maior possibilidade deficar sozinha, sendo o elemento de referência familiar. A predominância de núcleos familiares simples é corroborado por Walsh (1995, p. 269). Segundo a mesma, $80 \%$ das que vivem sozinhas; são mulheres mais velhas, geralmente viúvas. A autora ainda relata que as mulheres têm maior probabilidade de enviuvar numa idade menos avançada, com muitos anos de vida ainda pela frente.

A repercussão destes dados para a saúde é importante, uma vez que a literatura destaca que a família cuja mulher é o chefe pela ausência do marido/companheiro, tem maiores dificuldades em função da menor renda e de que o fato de que a idosa apresenta mais problemas de saúde. Na região metropolitana de Fortaleza, este percentual, para a população feminina em geral chega a 22,7\% das famílias. Estas famílias possuem renda per capita de até 1 salário mínimo em $66,9 \%$ do total enquanto nas família em geral esta classe de renda é de $57,0 \%$ (IBGE/PNAD, 2001). 
$\mathrm{Na}$ expectativa do aumento da longevidade, é importante que a esposa/companheira tenha condições de prestar cuidados em situações de dependência, temporária ou permanente, uma vez que faz parte da cultura e é esperado que a mulher seja cuidadora de eleição do esposo nestas circunstâncias.

En la mayoría de las familias es una única persona la que asume la mayor parte de la responsabilidad deloscuidados. La mayor parte de estos cuidadores principales son, como se ha visto, mujeres: esposas, hijas y nueras (UAM, 2002).

Esta também é a nossa realidade. No nosso estudo, ainda em fase de conclusão, sobre o cuidador observamos que $88,8 \%$ dos 384 cuidadores familiares entrevistados são muIheres, predominantemente na faixa etária de 40 a 59 anos (43,4\%) e 70 (18,2\%) acima de 60 anos.

\subsection{Estrutura familiar}

Segundo dados da Pesquisa Nacional de Amostragem Domiciliar (IBGE, 2001) a família nuclear representa 39,6\% entre os idosos; famílias incompletas representam $17,9 \%$ e extensa $31,8 \%$ e $10,6 \%$ dos idosos residem sozinhos na região metropolitana de Fortaleza, seguindo o padrão brasileiro e aos dados encontrados na pesquisa.

A relevância da estrutura familiar para a enfermagem surgequando énecessário se trabalhar com rede familiar de apoio, especialmente no cuidado ao idoso dependente. As famílias nucleares são mais receptivas para assumirem este cuidado. Quando o idoso re side sozinho esta preocupação é acentuada, sendo necessário mobilizar a rede social de apoio (M ailloux-Poirier, 1995), como já o fizemos em algumas ocasiões com idosos do nosso grupo de convivência. Neste momento, o conceito de família deve ser ampliado para abarcar as demandas do idoso, incluindo vizinhos e pessoal dos serviços de saúde aos quais o idoso está adstrito ( $M$ oraes; Silva, 2004).

\subsection{Renda familiar dos idosos entrevistados}

Segundo dados do PNAD (2001), na região metropolitana de Fortaleza, 14,9\% dos idosos possui renda familiar de até meio salário mínimo e 44,5\% até 1 salário mínimo per capita. A relevância deconhecimento da renda familiar está nos aspectos ligados às necessidades decorrentes do processo de envelhecimento. N esta fasehá um requerimento maior de medicamentos, alimentação e outros custosque os processos limitativos acarretam. No momento em queo idoso precisa mais de seus recursos para seu próprio benefício, ele se vê diante da necessidade de amparar parentes desempregados ou doentes. Se observarmos que $25 \%$ dos nossos entrevistados sustentam suas famílias com seu benefício de 1 salário mínimo, é provável que ele esteja entre os $14,9 \%$ mais pobres.

Pesquisa realizada em cidade interiorana do Estado demonstra que estes recursos não são direcionados para suas necessidades, mas sim àsfamiliarese, muitas vezes, o idoso nem chega a tomar posse deste dinheiro pois éum familiar seu quem fica com o cartão que dá direito ao saquemensal do valor. Estetem sido um dos problemas de maior dificuldade de enfrentamento pelosidosos e pelos profissionais de saúde que os têm como clientes (Sobreira; Silva, 2001).

\subsection{Caracterização dos membros das famílias dos idosos}

A predominância deresidentesidosos nas famílias dos entrevistados confirma a literatura que destaca que hoje é comum um idoso cuidando do idoso, muitas vezes os dois sendo carentes de cuidados.

A idade de permanência na casa dos pais 
no Brasil ésuperior aos países desenvolvidos, quando aos 22 anosjáse considera uma saída tardia. No Brasil o divisor de águas e 26 anos (Camarano, El Ghaouri, 2003). A falta deuma política social que ampare os idosos dependentes faz com que a família assuma grande parte dos cuidados com seus segmentos dependentes: "este cuidado se traduz, em parte, pela co-residência o que, em certas situações, beneficia as gerações mais novase, em outras, as mais velhas".

O bservamos, como agravante da situação, que quando mais a mulher idosa precisa de pessoas a sua volta, a família está menor. Só a partir dos 80 anos temos um aumento significativo, para o que atribuímos o início da dependência física ou psicológica, quando, necessariamente, ou a família vem morar com ela ou ela se muda para a casa de um filho ou parente. Diferentemente do que acontece em outros países, a mulher é mais amparada que o homem, no nosso caso parece que um segundo casamento do homem ajuda a manter um número maior de membros sub o mesmo teto que o idoso, também contribuindo para isso uma maior rendimento familiar nas famílias dosidosos.

A guisa de síntese, o que foi evidenciado no estudo em pauta, embora o reduzido número amostral possa trazer prejuízos à generalização, é que o idoso de baixa renda, foco deste trabalho, convive com uma estrutura familiar que não Ihe dá muitos recursos para a manutenção de sua autonomia, principalmente a referente a disponibilidade de recursos financeiros. A preocupação que a pessoa idosa tem em não ficar dependente, o que é um divisor de águas entre ser velho (dependente) e idoso (com idade avançada mas autônomo) é que ele tem clareza das condição adversasquesua família, pobre, pequena, sem muitos recursos sociais, muito embora a afetividade que nelas são presentes não seja discutida neste espaço de análise mas que é um aspectos extremamente relevante para nosso idoso. Há um adágio popular que diz: ruim com ela, pior sem ela. A solidão ea pers- pectiva de viver só é aceitável quando a rede social de apoio ésólida, abundantee a família tem este papel de prover, amparar e garantir uma velhicebem sucedida. A enfermagem tem uma importante participação na construção desta estrutura de apoio ao idoso e o conhecimento de sua realidade é o primeiro passo para uma intervenção eficaz e eficiente.

\section{REFERÊNCIAS BIBLIOGRÁFICAS}

ARAÚJO, A. R. (2003) . O Cuidador familiar deidosos: uma abordagem compreensiva. Dissertação de mestrado em Enfermagem Comunitária. Programa de Pós-graduação em Enfermagem. Departamento de Enfermagem/ UFC. Fortaleza, $185 \mathrm{p}$.

BRASIL (2003). Constituição Federal, Consolidação das leis do trabalho, legislação previdenciária. 4 ed. São Paulo: Editora Revista dos Tribunais.

BRASI L, LEI 10.741/2003 (Lei ordinária) 01/10/2003. Dispõe sobre o Estatuto do idoso e dá outras providências. Texto disponível na Internet no site: http://www.planalto.gov.br/ccivil-03/leis/2003/ L10.741.htm

BRASI L. LEI 8.842 de 4 de janeiro de 1994. Dispõe sobre a Política Nacional do Idoso, cria o Conselho Nacional do Idoso e dá outras providências. Diário Oficial da União. Brasília, 5 dejaneiro 1994, seção 1.

CAM ARAN O, A. A.; El Ghaouri, S. K. (2002). Famílias com idoso: ninhos vazios? Brasília: IPEA. Textos para discussão $\mathrm{n} 0950$.

FU N DAÇÃO GETÚ LIO VARGAS (1986). Dicionário de ciências sociais. Rio de Janeiro: FGV.

HAYFLICK, L. (1997). Como e porque envelhecemos. Rio de Janeiro: Campus.

IBGE (2001). Pesquisa Nacional de Amostragem Domiciliar. Disponível na Internet. 2000/população/ pop-censo2000" http://www.ibge.gov.br/home/ estatistica/população/censo2000/população/popcenso2000pdf . Pesquisa em 8 de abril de 2004.

M AILLOU X-POIRIER, D. (1998). Aspectos demográficos e epidemiológicos do envelhecimento. In. Berger, L.; M ailloux-Poirier, D. Pessoas idosas. Uma abordagem integral. Lisboa: Lusodidacta, 1995. pp. 87-98.

M EDEIROS, M.; Osório, R. (2002). Mudanças nas famílias brasileiras: composição dos arranjos domiciliaresentre1978 e1998. Brasília: IPEA. Textospara discussão 으 886.

MINISTÉRIO DA PREVIDÊNCIA E ASSISTÊNCIA SOCIAL (1997). Plano Integrado e ação governa- 
mental para o Desenvolvimento da política nacional do idoso. Brasília: M PAS/ SAS.

MINISTÉRIO AS SAÚDE. CONSELHO NACIONAL DE SAÚDE (2004). Resolução no 196 de 10 de outubro de 1996. Disponível no site: http:// conselho.saude.gov.br/docs/Resolucoes/Reso196. doc.; Pesquisa em 13 de abril de 2004.

M ORAES, G. L. A.; Silva, M. J. (2004). Explorando o universo do cuidado de idoso dependente pelo cuidador familiar. A provado para publicação na Revista RENE. No prelo.

NACIONESUNIDAS (2000). Año Internacional delas personas de edad. Principios de las Naciones U nidas a favor de las personas de edad. Documento disponível na internet. Site http:www.un.org/ese/ socdev/tyop/isiyoppo.htm. Acesso em julho de 2000.

NERI, A. L. (1999). Qualidade de vida no adulto maduro. Interpretações teóricas e evidências de pesquisa. In NERI. A. L. (org), Qualidadedevida eidade adulta. 2 ed. Campinas: Papirus, pp. 9-56.

SILVA, M.J. (2001). Autonomia e Saúde M ental. 0 desafio para uma velhice bem sucedida. Tese de dou- torado em Enfermagem. Programa de Pós-graduação em Enfermagem. Departamento deEnfermagem/ U FC. Fortaleza, 287 pp.

SOBREIRA, E. S.; Silva, M. J. (2001). 0 idoso no cotidiano. Um estudo na cidade do I guatu. In. Fraga, M. N. O.; Braga, V. A. B. ;Sousa, A. M. A. Políticas desaúde, saúdemental einterdisciplinaridade: avaliação emétodos. Fortaleza: Pós-graduação DENF/ UFC/FCPC, p. 139-149.

TURINI, R.T. N .; M arra, C. C.; Murai, H. C. etal. (2002). Avaliando a assistência ao idoso: a construção de um formulário para coleta de dados. In Cianciarullo, T. I. (org), Saúde na família e na comunidade. São Paulo: Robe editorial, pp. 340-376.

WALSH , F. (1995). A Família no estágio tardio devida. In Carther, B.; M cGoldrick, M. (col.). As mudanças no ciclo de vida familiar. U ma estrutura para a terapia familiar. 2 ed. Porto Alegre: Artes M édicas. Capítulo 14, pp. 269-287.

WRIGHT, L.; Leahey, M . (2002). Enfermeiras e Famílias: Um guia de Avaliação e Intervenção na Família. Rio de Janeiro: Editora Rocca. 